\title{
Egyptian Females' Experience in Interventional Radiology Field
}

Women have been historically underrepresented in interventional radiology (IR) all over the world. Even though the prevalence of female radiologists has increased in the past few decades, there remains remarkable shortage of female IR physicians in the United States, Europe, and more notably in developing countries. ${ }^{[1-4]}$

According to the 2016 UK Radiology workforce census, 35\% of consultant radiologists and 39\% of trainees are female, but only $10 \%$ of the current IR consultants are females. ${ }^{[2]}$

In addition, in the USA, women are underrepresented in the radiology field and even more in IR specialty representing $27 \%$ and $8 \%-12 \%$, respectively. ${ }^{[3]}$

While in Canada, a survey performed in 2015 revealed that only $1.5 \%$ of female Canadian medical students chose radiology as a specialty versus $5.6 \%$ of men. ${ }^{[4]}$

Recent surveys have shown that many female patients prefer physicians of their same gender. ${ }^{[5]}$ Egypt as well as other Arab countries hold a conservative community culture, so the demand for female IR doctors to treat female patients has increased in these countries.

We surveyed the largest 19 university, governmental, and military medical institutes in Egypt with well-equipped catheterization labs that offer therapeutic IR services.
Female IR consultants represent 5.9\% (6/101) of all IR consultants in the surveyed universities, whereas females represent $11.7 \%(10 / 85)$ of all IR fellows and $34.4 \%(21 / 61)$ of all IR residents [Table 1].

Currently, IR training in Egypt is institution based and there is no nationwide structured IR fellowship program. However, there is IR training program during the residency period in Ain Shams University. This IR training program allows residents to spend 4-6 months of their 3-year residency in the IR unit together with being enrolled in 24/7 shifts schedule. This training makes them eligible to choose IR fellowship later.

Despite the fact that gender bias is on the decline in Egypt and other Arab countries, several factors may contribute to the underrepresentation of women in IR specialty. These include the nature of IR and stress related to it, work-life balance and disproportion, the cultural belief that women should work part time to meet childcare needs, and subsequently the low number of female mentors. ${ }^{[6]}$ Besides, concerns related to radiation exposure in interventional radiology and its potential hazards and impact on fertility may influence the choice of IR as a profession. ${ }^{[6]}$

On the other hand, there seems to be increasing interest in joining IR specialty in Egypt in the past few years.

Table 1: Number of interventional radiology resident, fellows, and consultants in 19 major hospitals and universities representing Egypt

\begin{tabular}{|c|c|c|c|c|c|c|}
\hline \multirow[t]{2}{*}{ University } & \multicolumn{2}{|c|}{ IR consultants } & \multicolumn{2}{|c|}{ IR fellows } & \multicolumn{2}{|c|}{ IR residents } \\
\hline & Male & Female & Male & Female & Male & Female \\
\hline Ain Shams University, Cairo & 24 & 0 & 18 & 6 & 11 & 13 \\
\hline El Kasr El Einy University, Cairo & 14 & 1 & 5 & 0 & 5 & 0 \\
\hline Alexandria University & 7 & 0 & 4 & 0 & 0 & 0 \\
\hline Al Azhar University, Cairo & 2 & 0 & 2 & 0 & 0 & 0 \\
\hline Al Mansoura University & 6 & 3 & 6 & 1 & 4 & 5 \\
\hline Al Zakazik University & 4 & 0 & 6 & 0 & 6 & 0 \\
\hline Assiut University & 5 & 1 & 5 & 0 & 0 & 0 \\
\hline El Menya University & 4 & 0 & 1 & 0 & 0 & 0 \\
\hline Sohag University & 1 & 0 & 1 & 0 & 0 & 0 \\
\hline South Valley University, Quina & 1 & 0 & 0 & 0 & 0 & 0 \\
\hline El Suez University, Ismailia & 3 & 1 & 4 & 2 & 0 & 0 \\
\hline Tanta University & 2 & 0 & 3 & 0 & 0 & 0 \\
\hline Health Insurance hospital at Nasr City, Cairo & 1 & 0 & 3 & 0 & 3 & 0 \\
\hline Theodor Bilharz Research Institute, Cairo & 1 & 0 & 3 & 0 & 0 & 0 \\
\hline National Hepatology and tropical medicine research institution, Cairo & 5 & 0 & 2 & 1 & 3 & 0 \\
\hline National Cancer Institute, Cairo & 6 & 0 & 7 & 0 & 4 & 3 \\
\hline Maadi Military Hospital, Cairo & 6 & 0 & 3 & 0 & 0 & 0 \\
\hline Al Azhar University, New Damietta & 1 & 0 & 1 & 0 & 0 & 0 \\
\hline National Liver institute, Sheben El-Kom & 2 & 0 & 1 & 0 & 0 & 0 \\
\hline Total & 95 & 6 & 75 & 10 & 40 & 21 \\
\hline
\end{tabular}

IR: Interventional radiology 
This could be attributed to the increased awareness about IR at both public and medical levels, which lead to increased demand for female doctors in Egypt. Furthermore, the late timing of marriage in Egypt delayed the fertility-related concerns by female graduates pursuing IR profession. Besides, the presence of flexible work schedules in many institutes and the option to take maternity leave has facilitated the completion of IR training. Another factor that may attract females to pursue IR as a specialty is the presence of female mentors, supportive work environment, and program directors as in the case of Ain Shams University where females constitute $54 \%(13 / 24)$ of the total IR residents and $25 \%(6 / 24)$ of IR fellows. Females at Ain Shams University hospital have joined the IR field recently, so no female IR consultants were counted so far. However, the growing proportion of females in this field is expected to increase the number of female consultants in the near future.

Major international IR societies such as the Society of Interventional Radiology, the Pan Arab Interventional Radiology Society, and the Cardiovascular Interventional radiology society in Europe have realized the importance of females in IR field and have recently made it a priority to recruit more females into the specialty and reach out to female members to be more visible within the societies. IR societies currently play a considerable role in promoting and supporting female IRs and increasing their participation in IR meeting sessions as speakers and moderators, which helps recruiting more females to the field all over the world including Egypt. ${ }^{[7]}$

\section{Acknowledgment}

The author would like to acknowledge Prof. Dr. Sameh Abd El Wahab, MD, Radiology department, IR unit, Ain Shams University Hospital, and Dr. Karim Abd El Tawab, MD, Radiology department, IR unit, Ain Shams University Hospital, for their continuous support to female IRs in Ain Shams University hospitals.
Rana T. M. Khafagy

Department of Radiology, IR Unit, Ain Shams University Hospital, Cairo, Egypt.

E-mail: ranatarek@hotmail.com

\section{References}

1. Jaschke W, Bartal G, Trianni A, Belli AM. Fighting the gender gap in interventional radiology: Facts and fiction relating to radiation. Cardiovasc Intervent Radiol 2018;41:1254-6.

2. Belli AM, Englander M. The female threat. Cardiovasc Intervent Radiol 2018;41:673-4.

3. Kumari D, Walker L, Bochnakova T. Women in interventional radiology: Factors that influence women to pursue IR. J Vasc Intervent Radiol 2018;29:172.

4. Zener R, Lee SY, Visscher KL, Ricketts M, Speer S, Wiseman D. Women in radiology: Exploring the gender disparity. J Am Coll Radiol 2016;13:344-50.e1.

5. Barden LS, Teutsch CB, Barden RS. The role of gender in patient preferences and satisfaction with the patient-physician relationship. J Am Med Womens Assoc 2000;55:39.

6. SCAI Women in Innovations, Considerations for Female Interventional Cardiologists. Available from: https://www.bcs. com/documents/Z1E_WIN_FemaleInterventionalists_FINAL[1]. pdf. [Last accessed on 2018 Dec 15].

7. Englander MJ, Belli AM. Women can lead the way for the future of interventional radiology. Endovasc Today 2018;17:78-80.

This is an open access journal, and articles are distributed under the terms of the Creative Commons Attribution-NonCommercial-ShareAlike 4.0 License, which allows others to remix, tweak, and build upon the work non-commercially, as long as appropriate credit is given and the new creations are licensed under the identical terms.

\begin{tabular}{|l|l|}
\multicolumn{2}{|c|}{ Access this article online } \\
\hline Quick Response Code: & Website: \\
& www.arabjir.com \\
\cline { 2 - 2 } & DOI: \\
\hline
\end{tabular}

How to cite this article: Khafagy RT. Egyptian females' experience in interventional radiology field. Arab J Intervent Radiol 2019;3:1-2. 